\title{
Há verdade na ficção? - uma discussão com Coelho em crise de John Updike
}

\author{
Is there truth in fiction? - a discussion with John \\ Updike's Rabbit redux novel
}

\section{Leandro Thomaz de Almeida}

Doutor em Teoria e História Literária Universidade Estadual de Campinas

leandroth@gmail.com

Resumo: Discute-se no presente artigo as possibilidades de conhecimento sobre a história proporcionadas pelos discursos historiográfico e literário. De proporções gigantescas, o tema foi obviamente abordado a partir de um enfoque delimitado. Em um primeiro momento, procura-se apontar alguns problemas de se alçar a escrita ficcional ao estatuto de documento, ocasião para se criticar o uso da literatura como fonte de conhecimento no mesmo sentido em que a história se utiliza de documentos para fazer afirmações sobre o passado. Em seguida, após uma vista d'olhos sobre a discussão historiográfica propriamente dita, propõe-se uma possibilidade de conhecimento a partir da literatura, tendo em vista o romance de John Updike.

Palavras-chave: Literatura, História, Conhecimento, John Updike

\begin{abstract}
This article discusses the possibilities of knowledge about the history provided by the historiographic and literary discourses. Of gigantic proportions, the subject has obviously been approached from a delimited point of view. At first, we try to point out some problems of use fictional writing as having document status, occasion to criticize the use of literature as a source of knowledge in the same sense in which history uses documents to make statements about the past. Then, after an eye on the historiographical discussion itself, it is proposed a possibility of knowledge from the literature, in view of John Updike's novel.

Keywords: Literature, History, Knowledge, John Updike
\end{abstract}


[...] os fatos são por vezes menos sagrados do que se pensa $[\ldots]$

(LE GOFF, 2003: 31)

\section{I}

Em um dos capítulos de seu Ensaio sobre Heidegger e outros, Richard Rorty propõe um exercício de reflexão que servirá de motivo para minhas considerações iniciais. No parágrafo de abertura de "Heidegger, Kundera e Dickens", ele convida:

Imaginem que as nações que compõem o que nós chamamos 'Ocidente' desaparecessem amanhã, exterminadas por bombas termonucleares. Só o Leste Asiático e a África subsaariana permanecem habitáveis, e nessas regiões a reação à catástrofe é uma implacável campanha de desocidentalização - uma tentativa razoavelmente bem sucedida de obliterar a memória dos últimos três séculos. Mas imaginem também que, em meio à campanha de desocidentalização, algumas poucas pessoas, a maioria nas universidades, procurem armazenar tantos souvenirs do Ocidente quanto elas puderem - tantos livros, revistas, pequenos artefatos, reproduções de obras de arte, filmes de cinema, videotapes, e assim por diante, quanto elas puderem manter escondidos. Agora imaginem que, por volta de 2500, a memória da catástrofe esvaece, os porões lacrados são descobertos, e artistas e estudantes começam a contar estórias sobre o Ocidente. Haveria estórias muito diferentes, com muitas morais diferentes (RORTY, 1999: 95).

Essa cena apocalíptica é o ponto de partida para que Rorty continue alimentando sua filosofia, incansavelmente crítica de uma tradição muito forte no pensamento ocidental, aquela que, no fim das contas, segundo sua visão, estaria sempre em busca da Realidade, assim, em maiúscula, em oposição às realidades contingentes, fragmentadas, absolutamente dependentes de nossos jogos de linguagem para se constituir enquanto tal, que são as que o filósofo entende compor nossa experiência no mundo. Mas, como o que me interessa no momento não é me deter nos aspectos próprios à discussão filosófica do pragmatismo encampada por Rorty, gostaria de apontar os elementos que me são mais caros nesse texto.

Grosso modo, como forma de manter histórias que seriam representativas desse imaginado Ocidente que se espera desenterrar da catástrofe, Rorty propõe que a 
narrativa de Charles Dickens seria preferível à filosofia de Martin Heidegger, caso houvesse apenas uma opção a ser feita. Sua argumentação, sempre tendo em vista a imagem inicial proposta, alega que "Dickens poderia ajudá-los a apreender um complexo de atitudes que foram importantes para o Ocidente, de um modo que nem Heidegger, nem qualquer outro filósofo poderia" (RORTY, 1999: 97). Esse "complexo de atitudes" seria aquele presente nos personagens dickensianos, pelos quais o escritor "atacou casos concretos de pessoas em particular que ignoraram o sofrimento de outras pessoas em particular" (RORTY, 1999: 110). O desfile desses personagens seria capaz de criar identificação, apta, talvez, a gerar um sentimento de empatia junto a seus leitores. Rorty: "nós desejamos que todos os líderes das revoluções bem-sucedidas tivessem lido menos livros que lhes dessem ideias gerais e mais livros que lhes dessem a capacidade de se identificar imaginativamente com aqueles que eles têm de governar" (RORTY, 1999: 111).

A literatura, desse modo, poderia oferecer a apreensão de um "complexo de atitudes", presente na ação de personagens que, em Dickens, sofreram as maiores agruras, como a orfandade, o abandono, a pobreza (que se pense em Oliver Twist, por exemplo), o qual poderia gerar uma "identificação imaginária" que, ao fim e ao cabo, seria responsável por forjar atitudes concretas em direção a mais inclusão e generosidade: "se nós fizermos de Dickens o paradigma do Ocidente, como eu acho que meus africanos e asiáticos fantasiosos o fariam, então nós veremos que o aspecto mais instrutivo na recente história do Ocidente é sua crescente capacidade de tolerar a diversidade" (RORTY, 1999: 112) ${ }^{1}$.

A proposta de Rorty, ressalte-se, ao privilegiar Dickens no lugar de Heidegger, significa uma provocação e tanto, que, de cara, já nos traz algumas questões. A primeira delas remete a um certo equilíbrio de pratos na balança das relações entre literatura e

\footnotetext{
${ }^{1}$ É importante salientar que esse otimismo rortyano quanto ao que seria uma herança do Ocidente otimismo incômodo, se considerarmos, para ficarmos em apenas um exemplo, as empreitadas colonialistas a que deu origem - é notado pelo próprio Rorty, que oferece uma nuance ao desenvolvimento de seu raciocínio que acho importante deixar registrada: "Pode parecer estranho atribuir esse tipo de boa vontade ao Ocidente recente - uma cultura frequentemente citada, com excelente razão, como sendo racista, sexista e imperialista. Mas ela também é claramente uma cultura que está muito preocupada quanto a ser racista, sexista e imperialista, tanto quanto a ser eurocêntrica, paroquial e intelectualmente intolerante. Ela é uma cultura que se tornou muito consciente de sua capacidade para a intolerância assassina; e, consequentemente, uma cultura que talvez tenha se tornado mais atenta frente à sua intolerância, mais sensível ao caráter desejável da diversidade, do que qualquer outra da qual nós tenhamos registro. Venho sugerindo que nós, ocidentais, devemos essa consciência e essa sensibilidade mais aos nossos romancistas do que aos nossos filósofos ou aos nossos poetas” (RORTY, 1999: 112).
} 
filosofia. Não é incomum que se "use" a literatura como ilustração de teses filosóficas e sociológicas; estas apontariam as questões teóricas e abstratas, aquela entraria como exemplo de sua realização, digamos, mais "concreta" ou "aplicada". A segunda sugere que a literatura desempenha algum tipo de papel relativo ao conhecimento, uma vez que ela seria capaz, de maneira mais eficiente que a filosofia mais canônica do século XX, de preservar algum tipo de princípio representativo do que teria sido o Ocidente.

Mas em que termos esse conhecimento proporcionado pela literatura pode ser colocado? Esse aspecto é fundamental para a discussão. Há um encaminhamento dela que me parece mais confundir que esclarecer, ou que, no mínimo, se utiliza de termos como se eles fossem intercambiáveis entre áreas diversas como história e literatura. Portanto, a digressão a seguir servirá para apontar o que me parecem ser maneiras equivocadas de tratamento da literatura quando ela é pensada em suas possibilidades de criar ou oferecer conhecimento.

Nessa digressão, vou evocar um exemplo com o qual trabalhei recentemente, relativo justamente à discussão envolvendo literatura e realidade, que é um aspecto decisivo quando se pensa a possibilidade de veiculação de conhecimento que a literatura encamparia. Trata-se de uma crítica a um modo de compreensão da chamada literatura naturalista. Como sabemos, a literatura que floresceu no último quarto do século XIX na França e teve como nome de maior destaque Émile Zola se propunha a ser uma descrição objetiva da realidade, capaz de oferecer ao leitor um retrato das coisas como elas eram de fato, sem que as fantasias do escritor interferissem no gesto de narrar o que está diante dos olhos. Ora, qualquer um que tenha estudado com um pouco de cuidado tanto o romance naturalista zolaniano (e me detenho aqui em Zola porque seria mais prudente falar em "naturalismos", mas isso nos levaria para longe do foco aqui abordado), quanto sua elaboração teórica, levantaria uma série de objeções a essa caracterização aqui feita do naturalismo. Eu mesmo seria um deles. Mas se coloquei as coisas nesses termos é porque parece ter tido vida longa, e permanece tendo, uma concepção nesses moldes do naturalismo, como se, no final das contas, o efeito de real presente na prosa romanesca do período, o alegado ideal de objetividade requerido por 
alguns escritores e a descrição minuciosa de lugares e situações fossem suficientes para fazer da literatura um documento sobre determinada realidade.

Vejamos, por exemplo, os termos que envolvem a produção literária do escritor brasileiro Inglês de Sousa. O autor ficou conhecido por abordar em seus romances a região amazônica, de onde era nativo (embora dela tenha se mudado aos onze anos de idade), com destaque à cidade de Óbidos, no Pará. A junção desses elementos, ou seja, uma descrição detalhada da natureza local, a caracterização das personagens nativas e seus costumes e o fato de ter sido um morador da região parecem ter sido suficientes para que a literatura do autor fosse vista como documento a respeito de determinada realidade. Na apresentação que fez a Inglês de Sousa - textos escolhidos, Bella Jozef afirmou que um dos méritos do seu romance seria o de ser "verdadeiro documento social" (1963: 14). E continua: "se houve regionalismo [em O coronel Sangrado] foi para, através dele, chegar à realidade, com figuras que [o autor] viu e observou, fugindo à imaginação" (1963: 15). Pedro Maligo, em Land of metaphorical desires - The representation of Amazonia in Brazilian Literature, faz afirmações que caminham em direção semelhante: "no contexto de uma literatura que pretende ser tanto informativa quanto artística é muito natural que o tratamento temático da Amazônia seja orientado em direção ao documentário" (1998: 12) ${ }^{2}$. Desse modo, a região seria "retratada muito objetivamente" (1998: 12), em romances como O cacaulista e O coronel Sangrado. Para não multiplicar os exemplos, encerro com o livro de Mauro Vianna Barreto, $O$ romance da vida amazônica - uma leitura socioantropológica da obra literária de Inglês de Sousa. Nas palavras de Peregrino Junior citadas pelo autor, a ficção comportaria um caráter de "documentário exato e minucioso da vida amazônica" (Peregrino Júnior, apud Barreto, 2003: 144). Nesse sentido, romances e contos do escritor amazonense são entendidos como "documento sociológico" (Barreto, 2003: 79), porque Inglês de Sousa "não escrevia seus romances pretendendo fazer apenas ficção, mas também esperava que espelhassem a realidade da forma mais exata possível" (Barreto, 2003: 77). Assim, o romance seria uma mistura de "literatura e crítica social, arte e ciência e de romance e antropologia" (Barreto, 2003: 202).

Não vou me deter em uma crítica detalhada dessas afirmações, o que foi feito de modo notável, tendo exemplos diferentes em perspectiva, por Lilian Furst em All is true: the claims and strategies of realist fiction (1995), mas chamo atenção aos termos

\footnotetext{
2 Todas as traduções, salvo indicação contrária, foram feitas pelo autor do artigo.
} 
que compareceram na discussão: "verdadeiro documento social"; "fugindo à imaginação"; "documentário exato"; "documento sociológico"; "não [...] fazer apenas ficção". Segundo entendo, são todos termos e afirmações inadequados para se referir à literatura, por incorrer em alguns problemas, não necessariamente em ordem de importância: dão a entender que literatura feita com pretensão de transmitir um efeito de real dá menos importância à imaginação, ou a suprimiria de algum modo; sugerem que a ficção, por si só, carece de importância, devendo ser suplementada por alguma função útil mais facilmente apontável; equivalem o discurso literário ao discurso historiográfico, na medida em que o tratam como documento. E aqui me parece residir um problema recorrente em abordagens da literatura que a tratariam como fonte de conhecimento sem qualquer nuance, ou seja, sem distinção entre gêneros literários e historiográficos, para ficar em um exemplo.

Ainda que entre os historiadores não haja ingenuidade quanto ao caráter textual e construído do documento ("todo documento é um monumento ou um texto, e nunca é 'puro', isto é, puramente objetivo" [LE GOFF, 2003: 30]), ele permanece sendo o elemento capaz de conferir veracidade a uma afirmação sobre a realidade. Equivaler a literatura a documento significa tomá-la como fonte de verdade. Mas, perguntamos, qual a possibilidade de verificação dessa verdade? Um exemplo simples de afirmação presente em um dos romances de Inglês de Sousa: “[entreteve-se Miguel] em apanhar as sementes saborosas da maravilhosa planta, que tanto entusiasmo causou ao viajante inglês Bridges, que lhe deu o nome da sua graciosa soberana" (SOUSA, 1968: 108). Miguel, personagem do romance $O$ coronel Sangrado, apanha as sementes de uma vitória-régia, a qual teria entusiasmado [provavelmente o botânico Thomas] Bridges, que, segundo o romance, teria visitado a região. De fato ele o fez? Alguém poria a mão no fogo por essa afirmação sem confirmá-la antes em algum livro de história, alguma biografia, algum relatório de algum museu naturalista? Qual a verificabilidade da afirmação presente em um romance? Ela não estaria presente justamente em outros gêneros de discurso, como o historiográfico, o científico, mesmo o testemunhal?

Discussões desse teor foram bastante estimuladas a partir dos escritos do historiador Hayden White. Como se sabe, White procurou mostrar que grandes historiadores "dissolve[ra]m a barreira - puramente convencional, em qualquer caso entre escrita histórica e escrita literária" (2014: 69). Mesmo não significando uma completa indistinção entre os gêneros historiográfico e literário, a proposta de White aproximou mais a história da literatura do que o contrário, na medida em que o 
conhecimento da história seria proporcionado por narrativas sempre correspondentes a algum "enredo", cujas linhas seriam traçadas por categorias literárias (tragédia, comédia, metáfora, ironia etc.): "dado evento singular, conjunto ou séries de eventos para serem qualificados como 'históricos', o evento, conjunto ou série precisa também ser validamente descritível como se tivessem os atributos de elementos em um enredo de uma história" (2014: 53). Assim, o relato historiográfico proporcionaria um conhecimento que só se poderia considerar objetivo sob muitas aspas.

Uma das reações mais enfáticas contra esse "ceticismo" de White veio de outro historiador, Carlo Ginzburg, que afirmou, com olhos voltados ao autor de Metahistória: "a contiguidade largamente aceita entre história e retórica empurrou para as margens a existente entre história e prova" (GINZBURG, 2002: 13). Mas o historiador italiano procura "corrigir os rumos", mostrando que a prova é um elemento fundamental do relato historiográfico. Ainda que o elemento retórico seja importante no discurso histórico, isso não levaria à desconsideração da necessidade da prova, necessidade essa que vigoraria, segundo Ginzburg, desde Aristóteles. Assim, mesmo na retórica, "a discussão sobre as provas tinha um papel essencial" (GINZBURG, 2002: 40). A associação entre história e retórica, mas sem considerar o importante papel desempenhado pela prova, é o que teria conduzido ao ceticismo contemporâneo quanto à possibilidade de conhecimento do passado. Assim, o embate White x Ginsburg é útil, também, para o desenvolvimento de meu argumento relativo à tomada da literatura como "documento": em que momento se pediria dela alguma comprovação de suas afirmações? À literatura está aberto o caminho para que ela seja retórica e nada mais. A ausência de provas em seu discurso inviabiliza sua equiparação à história, sociologia, antropologia etc. Para dizer de outro modo, a literatura não está sujeita aos critérios de verificação próprios do relato historiográfico, conforme as propostas de Wolfgang Mommsen evocadas por Jacques Le Goff em seu verbete "História" na Enciclopédia Einaudi:

a) foram as fontes pertinentes utilizadas e o último estágio de investigação foi levado em consideração? b) até que pontos estes juízos históricos se aproximaram de uma integração ótima de todos os dados históricos possíveis? c) os modelos explícitos ou subjacentes de explicação são rigorosos, coerentes e não contraditórios? (Wolfgang Mommsen apud LE GOFF, 2003: 31). 
Nenhuma dessas "condições de validade" se aplica à literatura. Ela segue constrições próprias do gênero, mas essas têm a ver com a organização interna dos elementos retóricos, não com correspondência fiel com aquilo que está fora do texto. Portanto, até aqui o que se viu é que fui, propositalmente, bastante cético quanto à possibilidade de se tomar a literatura como conhecimento no mesmo nível do discurso historiográfico quando este ampara documentalmente suas informações. Isso teve a intenção de marcar uma distância entre esses dois regimes de discurso. Mas minha posição final não é a de um ceticismo total em relação à possibilidade de que a literatura ofereça algum tipo de conhecimento.

Lançadas todas essas cartas na mesa, quero trazer à discussão justamente um romance, Coelho em crise, um dos livros da tetralogia de John Updike, que foi lançado no Brasil com os três outros títulos: Coelho corre, Coelho cresce e Coelho cai ${ }^{3}$. A escolha se deu por motivos bastante pessoais. Havia lido os quatro livros há mais ou menos quinze anos e trazia comigo a boa lembrança que a prosa de Updike, em excelente tradução, me despertava. Ainda sem ter a perspectiva de escrever o presente ensaio, reli os quatro livros, confirmando a ideia de que, em termos de romance, eram das coisas que mais me agradaram, além de ter ficado com a impressão de que Coelho em crise era o melhor deles (e também aquele em que a política está presente de maneira mais explícita - talvez por isso a preferência). E a pergunta que permaneceu após a leitura, que agora tenho a oportunidade de expressar e para a qual posso tentar organizar, se não uma resposta, um encaminhamento de raciocínio, era a de quais seriam algumas possibilidades de reflexão suscitadas pelo romance tendo em vista a questão acima apontada relativa ao conhecimento. $O$ que segue, portanto, são pensamentos em voz alta que têm como ponto de partida uma experiência de leitura, a qual, no entanto, aspira servir de contribuição para um determinando campo do saber no caso, aquele em que atuo, o da literatura.

Coelho em crise é o segundo livro da tetralogia, publicado em 1971. Os demais livros foram publicados em 1960 (Coelho corre), 1981 (Coelho cresce) e 1990 (Coelho cai). Cada um deles se passa em um ano de uma década específica, obedecendo a uma

\footnotetext{
${ }^{3}$ Originalmente, Rabbit, run; Rabbit redux; Rabbit is rich; Rabbit at rest.
} 
ordem progressiva: 1959, 1969, 1979, 1989. Acompanhamos, ao longo dos romances, a vida de Harry Angstrom, o Coelho, e neste Coelho em crise Angstrom está temporariamente separado de sua esposa Janice, com quem tem um filho, Nelson, que vai aparecer com mais destaque em Coelho cai.

$\mathrm{Na}$ ebulição social dos anos 60, encontramos, no relato historiográfico, a pretensão de compreender aquele momento, interpretá-lo em relação a acontecimentos anteriores e posteriores (Hobsbawm dizia que o olhar retrospectivo era a arma última dos historiadores), a apresentação de uma série de acontecimentos, dados demográficos, relatos de guerras, ascensão e queda de regimes, tudo isso - sem que se exima o historiador da necessidade de trabalhar com imaginação e criatividade - com a necessidade de dados, documentos, relatos, fontes comprobatórios. Tomemos como exemplo a afirmação do mesmo Hobsbawm:

a economia mundial na Era de Ouro continuou sendo mais internacional que transnacional. Os países comerciavam uns com os outros em medida cada vez maior. Mesmo os EUA, que tinham sido em grande parte auto-suficientes antes da Segunda Guerra Mundial, quadruplicaram suas exportações para o resto do mundo entre 1950 e 1970, mas também se tornaram um maciço importador de bens de consumo a partir do final da década de 1950. Em fins da década de 1960, começaram até a importar automóveis (1995: 271-2).

Para ter validade enquanto apresentação e interpretação de um período do passado, esses dados precisam ser verdadeiros. Se, hipoteticamente, se descobrisse que a importação de bens de consumo por parte dos EUA tivesse se iniciado apenas no final da década de 1960, e não 1950, conforme o trecho acima, ele perderia sua validade de explicação relativa a como os fatos se passaram naquele momento. $O$ relato historiográfico, assim, por mais que possa permanecer como exemplo de reflexão e modo de construção de argumentos - e essas características são marcantes no texto de Hobsbawm -, pode se tornar inválido.

E quando passamos ao romance? O que Coelho em crise, situado no final desses anos 60, por sua vez, nos oferece? A primeira diferença que salta aos olhos se o comparamos com o relato historiográfico é que ele não é "falsificável", por assim dizer; não perde sua validade: 
Chicago. Dois mil e quinhentos membros da Guarda Nacional de Illinois continuam de prontidão hoje, após um dia de conflitos de rua provocados por membros da facção extremista da organização estudantil Students for a Democratic Society. Vitrines foram quebradas, carros foram virados, policiais foram atacados por jovens militantes que gritavam a palavra de ordem [...] 'queremos a guerra aqui’ (UPDIKE, 1992: 242).

Nesse trecho do romance, ainda que a referência seja a uma Chicago real, tais fatos podem nunca ter ocorrido, mas, como o relato ocupa um lugar no "mundo do texto", para falar como Paul Ricoeur, eles sempre terão ali sua significação. Em outras palavras, o romance não é falsificável. Indo além dessa diferença básica entre o relato historiográfico e o literário, poderíamos falar com Rorty e dizer que o romance traz, pela representação da vida de Harry Angstrom e dos personagens de seu mundo, um "complexo de atitudes" existente naquele momento. O romance apresenta uma possibilidade de contato com a representação de vivências verossímeis daquele período a partir do enredo que escolheu construir. O que vem à tona não são os eventos históricos. Não é a guerra do Vietnã, a alta do petróleo, a crise com o Irã, os movimentos de emancipação feminina e de liberação das drogas, a cultura hippie. Mas isso tudo está presente, conformando a experiência das personagens e oferecendo uma possibilidade de interpretação (e/ou crítica, e/ou elogio etc.) de todos esses eventos, mas com uma vantagem: a literatura não precisa, para usar um termo que vi em Marisa Lajolo, "passar recibo" de suas afirmações. A literatura não se desatualiza se o dado histórico nela presente não estiver correto; permanece válida a representação de gestos humanos (situados, evidentemente; não se pensa aqui em termos abstratos em "humanidade") em situações específicas, e essa representação veicula crítica de uma forma poderosa.

Vamos pensar em alguns trechos de Coelho em crise que trazem temas de maneira polêmica, bem ao sabor dos momentos mais afiados da prosa de Updike. No primeiro deles, Harry Angstrom, o Coelho, já separado de sua esposa Janice, trouxe para casa uma jovem, Jill, que por sua vez trouxe um amigo, Skeeter. O capítulo do romance se inicia com o encontro entre Coelho e Skeeter. Este, negro, a todo momento provoca Coelho. Skeeter está foragido, sendo procurado pela polícia, e Jill espera que Coelho o receba em casa por uns dias. Mas a relação vai ser tensa: "Escuta. Coelho. Era assim que te chamavam, não era? Tua mãe é puta, certo? Ela chupa os mendigos 
crioulos atrás da estação do trem, cobra meio dólar por cabeça, certo? Se eles não têm meio dólar, ela faz de graça porque gosta, certo?” (UPDIKE, 1992: 186). A provocação continua em tom elevado:

'Teu pai é veado, certo? Você deve ser também, pra aguentar tanta provocação. Tua mulher não aguentava viver com um veado, era como ter que trepar com um rato, certo? Você tem um peruzinho de rato, deixe eu ver'. Estende a mão, Coelho a afasta com um tapa. Skeeter dança de felicidade. 'Não tem nada ali não, certo? Coelho. A Jill diz que tu acredita em Deus. Pois fica sabendo de uma coisa. Teu Deus é veado. Teu Deus branco é o mais veado dos veados. Ele chupa a pica do Espírito Santo e obriga o filho a assistir. Outra coisa. O tal do Jesus. Ele era um veado mentiroso, certo? Soltaram uma grana pros romanos pra pegarem o defunto dele porque estava fedendo demais, certo?' (UPDIKE, 1992: 187).

Mais do que provocação pura e simples, ou trecho escrito para escandalizar os leitores mais pudicos - mas nem tanto, porque o trecho é mesmo forte -, entendo que se pode ver aqui uma crítica de fundo ao estabelecimento de uma hierarquia racial. É como se Skeeter, negro, evidenciasse um desprezo brutal pela sacralidade da crença que, mesmo em meio a exceções, colaborou com a perpetuação da desigualdade racial em toda uma nação. Skeeter continua, ligando o elemento religioso ao explicitamente racial:

'Então vamos todos cantar 'Deus salve a América', certo? Norte e Oeste, explorador e explorado. O Sul virou um grande churrasco de crioulo. O Hitler, Deus o tenha, pelo menos escondia os fornos dele. Lá no Sul, em cada árvore tinha uma corda. Fizeram leis dizendo que se um negro espirrasse a cinco quilômetros da bunda de um branco ele era condenado a perder os colhões na boca dum cachorro treinado. O negro que não descia da calçada e lambia o escarro do branco mais fodido da cidade era posto a ferros e vendido pro cunhado do xerife, mais barato que ovo de jacaré. E se ele ousasse pedir o voto que a quinta emenda à Constituição garantia a ele, eles sempre davam um jeito de botar na bunda dele, melhor um crioulo enfiar a pica numa boceta de branca do que enfiar a cabeça dentro de uma cabine de votação. Certo? Chuck, eu tenho que admitir: vocês fizeram tudo certinho, todo mundo se deu bem. O Sul conseguiu reinstaurar a escravidão, só que agora pela metade do preço; voltou a 
controlar o Congresso contando os votos que não deixavam os negros pôr na urna; o Norte ficou com a grana do algodão que precisava para investir nas indústrias; e todo mundo teve o prazer de cagar em cima dos negros e depois prender a respiração" (UPDIKE, 1992: 206-207).

Se essas palavras não podem ser tomadas como relato absolutamente verídico houve mesmo leis dizendo que "se um negro espirrasse a cinco quilômetros da bunda de um branco ele era condenado a perder os colhões na boca dum cachorro treinado"? -, elas certamente têm o poder de interpretar uma situação e sugerir um modo de compreensão a seu respeito. Um modo crítico, mordaz, impiedoso de falar de uma realidade histórica, que desempenha o papel de manter na memória das pessoas de diferentes épocas como podem se dar as relações humanas e o grau absurdo de crueldade que elas podem alcançar. Essa liberdade da literatura lhe confere o poder de sugerir imagens que têm o poder de suscitar reflexões, debates, questionamentos sobre as relações sociais cujos efeitos experimentamos hoje. O que se vai fazer com isso é um problema de cada um. Racistas vão dizer que "é isso mesmo" e as coisas têm que continuar a ser desse modo - embora talvez o façam de maneira velada, porque coragem não é uma de suas marcas. Mas todos os que estamos interessados em relações sociais justas e igualitárias podemos aproveitar passagens como essa para lançar discussões sobre nossas atuais configurações sociais e nossas escolhas individuais. Elas nos provocam e, ao fazer isso, mantêm em pauta temas e despertam discussões sobre eles. É claro que o discurso historiográfico pode fazer a mesma coisa, mas o modo de dizer do romance, com sua liberdade para sugerir imagens e usar termos mormente interditados ao discurso historiográfico, é um de seus diferenciais. Que historiador, filósofo, sociólogo, psicólogo etc. poderia, em seu ofício, ter usado os termos usados pelo romancista?

Portanto, não se trata de uma concorrência entre verdades opostas, a da literatura e a da historiografia, mas das diferentes possibilidades de cada uma. Verdade enquanto aquilo a que se chega por meio de provas consideradas válidas pelo discurso historiográfico é algo interditado à literatura; por outro lado, lidar com liberdade com o material que a história oferece é um de seus alcances maiores. Essa liberdade com o material histórico que porventura escolha trazer para compor sua história é total; ela pode lançar juízos históricos de forma contrária ou favorável aos dados, ou mesmo se abster de fazê-lo, bem como não precisa seguir modelos de explicação. Ou, talvez, isso 
devesse ser dito de outro modo, porque, no fim das contas, a literatura não "recebe" material da história, porque está nela e contribui para sua elaboração. Não é como "reflexo" da realidade que a literatura desempenha seu papel, mas como sua constituinte. Ela faz isso de modos tão variados quanto possam ser as reações dos leitores aos livros que leem. Aponto dois desses modos aqui. O primeiro deles é a reflexão sobre a própria presença humana no mundo, que se dá pela representação de maneiras possíveis de se viver. Ao travar contato com essas maneiras, somos, enquanto leitores, levados a pensar nas semelhanças e diferenças entre o mundo elaborado pela literatura e o nosso, entre a reação das personagens e as nossas.

Em um segundo momento, decorrente desse primeiro, são postas em questão nossas filiações identitárias, nossas crenças, nossa visão a nosso próprio respeito. Como um leitor identificado com o cristianismo reage às palavras de Skeeter? Considera-as ofensivas e as repudia? Defende-se, procurando preservar-se das críticas? Entende que são legítimas dado o papel predominante do cristianismo em relação à escravidão e suas consequências? E um leitor agnóstico ou ateu? Sente-se contemplado pela maneira pouco respeitosa com que foram tratados símbolos religiosos? Qualquer que seja a reação, a indiferença dificilmente será uma delas. Há, assim, na literatura, e particularmente no romance, a reverberação das experiências históricas em indivíduos, ainda que esses sejam ficcionais. O que nos livros de história mormente aparece de maneira mais abstrata ("A era da guerra total", "Rumo ao abismo econômico" "Os anos dourados" etc. - apesar das exceções de sempre, como a microhistória celebrizada por um $O$ queijo e os vermes), no romance ganha a concretude da vivência individual ou grupal, pela representação delas.

Em um livro aparentemente para iniciantes - e que, na edição em português, infelizmente ganhou ares de manual -, Thomas Foster, professor de literatura na Universidade de Michigan, escreve sobre o romance aquilo que já ficou celebrizado a seu respeito, mas de um modo que reúne elegância e capacidade de síntese que acabam por mostrar afinidade com a proposta rortyana que abriu a reflexão aqui desenvolvida e com minhas próprias propostas inspiradas pelo romance de Updike. É um trecho longo, mas não gostaria de cortá-lo:

O que mais importa, talvez, em todos esses romances, e que faz o romance importante como um lugar de ideias, é a capacidade de trazer experiências de grande alcance para o nível individual. Grupos não levam vidas; as pessoas sim. 
Os filhos da meia-noite, de Rushdie, não é a história da "Índia" ganhando sua independência, é a história de Saleem Sinai, uma pessoa, a família em que nasce, suas experiências como indivíduo em uma nação emergente. É através dele que o coletivo pode ser expresso. Justo aí está a genialidade da forma romanesca. É o meio perfeito para capturar a existência individual e, por outro lado, um meio quase perfeito para captar a experiência do grupo. A vida da pessoa comum - aí está uma grande ideia, a primeira que o romance teve. As formas literárias anteriores eram altamente elitistas. A tragédia e o épico são, ambos, sobre a classe dos governantes, embora por razões bastante diferentes. A comédia, com frequência, tinha personagens menos nobres; não posso falar por vocês, mas meus ancestrais apareceriam em Shakespeare, se é que apareceriam, como coveiros e servos cômicos, a classe inteiramente dispensável cujo tempo no palco é contado em segundos. Mesmo a lírica era destinada às classes odiosas que podiam ler - pastores apareciam, mas ela não era para (nem mesmo sobre) pastores verdadeiros. Não, se seu sobrenome indicava o trabalho que você fazia ou onde o fazia - Miller, Cooper, Smith, Farrier, Forester, Forster ou Foster ${ }^{4}$-, você estava excluído da literatura antiga. Então, veio essa nova forma, abastecendo uma classe média emergente e, muitas vezes, sobre seus membros, e espaçosa o suficiente para ter lugar para quem realmente trabalha para viver. Ainda é melhor ter coisas do que fazer coisas, mas é um começo. Nenhum acaso nisso, no entanto: a ascensão do romance coincide com a ascensão de uma classe média, e da liberdade, e da democracia. Essa é uma forma na qual as pessoas comuns podem importar. Mas não é sobre uma classe - apenas sobre seus membros individuais. De fato, é a primeira forma na história da civilização ocidental a sugerir que uma única pessoa pode realmente importar no grande esquema, mesmo se essa pessoa não usar uma coroa" (FOSTER, 2011: 220-221).

A proposta de Foster, que reverbera nomes como os de Georg Lukács e Ian Watt, aponta para a possibilidade de o romance funcionar como palco da encenação da vida cotidiana. Esse palco, evidentemente, é pleno de conflitos, algo que não pode ser deixado de lado pelo cenário relativamente tranquilo proposto na síntese acima. Mas é justamente a encenação desses conflitos, ou, se pensarmos junto com o romance de

\footnotetext{
${ }^{4}$ Por ordem: oleiro, taneiro, ferreiro, ferrador, silvicultor, couteiro ou guarda-florestal. (Nota da edição).
} 
Updike, seu escancaramento, sua apresentação crua, sua ausência de panos quentes, que tem a capacidade de despertar modos de apreensão de nosso estar no mundo.

Em suas pesquisas sobre a leitura de jovens da periferia em bibliotecas francesas, Michèle Petit escreveu:

Desde a infância a leitura pôde, dessa maneira, representar para estes jovens o espaço de abertura para o campo do imaginário, o lugar de expansão do repertório das identidades possíveis, enquanto que os que estavam nas ruas tinham por modelos apenas alguns heróis de filmes de série $\mathrm{B}$, o traficante de drogas se pavoneando em seu BMW e o fundamentalista islâmico (PETIT, 2008: 74).

Gostaria de aproveitar, finalmente, essa expressão: “expansão do repertório das identidades possíveis". Como modo de reunir toda a discussão aqui proposta, ela me soa como uma das possibilidades mais importantes possíveis à literatura. Trata-se de um modo de conhecimento não só do tema nela presente, mas do "si mesmo" do próprio leitor e de seu lugar na sociedade. É uma possível verdade da ficção.

\section{Referências bibliográficas}

BARRETO, Mauro Vianna (2003). O romance da vida amazônica - uma leitura socioantropológica da obra literária de Inglês de Sousa. Presidente Venceslau, SP: Letras à margem.

FOSTER, Thomas C. (2011). Para ler romances como um especialista. Tradução: Maria José Silveira. São Paulo: Lua de Papel.

FURST, Lilian R. (1995). All is true: the claims and strategies of realist fiction. Durham: Duke University Press.

GINZBURG, Carlo (2002). Relações de força: história, retórica, prova. São Paulo: Companhia das Letras.

HOBSBAWN, Eric (1995). Era dos extremos: o breve século XX: 1914-1991. tradução de Marcos Santarrita. São Paulo: Companhia das Letras.

JOZEF, Bella (1963). Apresentação. In: Inglês de Sousa - textos escolhidos. Rio de Janeiro: Livraria Agir Editora.

LE GOFF, Jacques (2003). História e memória. Tradução de Bernardo Leitão [et. al.]. $5^{\text {a }}$ edição. Campinas, SP: Editora da Unicamp.

MALIGO, Pedro (1998). Land of metaphorical desires - The representation of Amazonia in Brazilian Literature. New York: Peter Lang.

PETIT, Michèle (2008). Os jovens e a leitura: uma nova perspectiva. Tradução de Celina Olga de Souza. São Paulo, Ed. 34.

RORTY, Richard (1999). Ensaios sobre Heidegger e outros. Tradução Marco Antônio Casanova. Rio de Janeiro: Relume Dumará. 
SOUSA, Inglês de (1968). O coronel Sangrado (Cenas da vida do Amazonas). Belém: Universidade Federal do Pará.

UPDIKE, John (1992). Coelho corre. Tradução de Paulo Henriques Britto. São Paulo: Companhia das Letras.

UPDIKE, John (1992). Coelho em crise. Tradução de Paulo Henriques Britto. São Paulo: Companhia das Letras.

UPDIKE, John (1992). Coelho cresce. Tradução de Sérgio Flaksman. São Paulo: Companhia das Letras.

UPDIKE, John (1992). Coelho cai. Tradução de Paulo Henriques Britto. São Paulo: Companhia das Letras.

WHITE, Hayden (2014). The Practical Past. Evanston: Northwestern UP.

Artigo recebido em 29 de janeiro de 2019.

Aprovado em 19 de maio de 2019.

DOI: $10.12957 /$ intellectus.2019.40681 